Review

\title{
Serum Triglycerides and Atherosclerotic Cardiovascular Disease: Insights from Clinical and Genetic Studies
}

\author{
Hayato Tada *, Atsushi Nohara and Masa-aki Kawashiri \\ Division of Cardiovascular and Internal Medicine, Kanazawa University Graduate School of Medical Sciences, \\ 13-1 Takara-machi, Kanazawa 920-8641, Japan; a-nohara@med.kanazawa-u.ac.jp (A.N.); \\ mk@med.kanazawa-u.ac.jp (M.-a.K.) \\ * Correspondence: ht240z@sa3.so-net.ne.jp; Tel.: +81-76-265-2000 (2251); Fax: +81-76-234-4251
}

Received: 27 October 2018; Accepted: 14 November 2018; Published: 17 November 2018

\begin{abstract}
Lipoproteins are a major risk factor for atherosclerotic cardiovascular diseases (ASCVD). Among the lipoproteins, low-density lipoproteins (LDL) have been shown to be causally associated with ASCVD development. In contrast, triglycerides or triglyceride-rich lipoproteins receive less attention than LDL because there is little definite evidence from randomized controlled trials. A Mendelian randomization study has recently been published in which a causal association could be estimated with observational datasets. Using such Mendelian randomization studies, ranging from common to rare genetic variations, triglycerides seem to be causally associated with ASCVD outcomes independent of LDL. Although the "causal association" of serum triglycerides and ASCVD is difficult to assert, accumulated evidence from clinical and Mendelian randomization studies, using common and rare genetic variations, strongly supports such an association. In this article, we provide a summary of investigations focusing on important causal associations between serum triglycerides and ASCVD from the clinical point of view.
\end{abstract}

Keywords: remnant lipoproteins; triglycerides; cholesterol; genetics

\section{Introduction}

Low-density lipoprotein (LDL) cholesterol has been shown as a causal risk factor for atherosclerotic cardiovascular diseases (ASCVD). Over the decades, LDL-lowering therapies including statins, ezetimibe, and proprotein convertase subtilisin-kexin type 9 (PCSK9) inhibitors, have been introduced in clinical settings and have contributed to better prognosis [1-3]. In addition to LDL cholesterol, triglyceride-rich lipoproteins are also considered important causal risk factors for ASCVD [4], and are usually considered one of the major "residual" risk factors of standard LDL-lowering therapies [5]. However, triglycerides or triglyceride-rich lipoproteins are not attracting sufficient attention from researchers and physicians, particularly from cardiologists who should carefully assess patient risk [6]. This may be because there are only a few randomized controlled trials (RCTs) supporting causal associations between triglycerides and ASCVD outcomes. In this article, we provide evidence from various approaches, including clinical data and common to rare variations in human genetics, supporting the conclusion that serum triglycerides are a causal residual risk factor for ASCVD.

\section{What Are Triglycerides?}

A triglyceride consists of glycerol and three fatty acids [7]. In the liver, triglyceride hydrolysis provides fatty acids for $\beta$-oxidation, signaling, and substrates for the assembly of very low-density 
lipoprotein (VLDL) triglycerides. Triglycerides cannot penetrate into cell membranes. A special enzyme located on the blood vessel walls called lipoprotein lipase (LPL) catabolizes those triglycerides to free fatty acids and glycerol. Triglycerides are not present in the blood per se because they are hydrophobic. Triglycerides are one of the major components of apolipoproteins, such as chylomicron, VLDL, intermediate-density lipoprotein (IDL), LDL, and high-density lipoprotein (HDL) (Figure 1). Accordingly, we need to consider which apolipoproteins are increased or decreased and which apolipoproteins are associated with human diseases.

\section{Cholesterol \\ Triglyceride \\ Phospholipid \\ Apolipoprotein}

Density $<0.95$

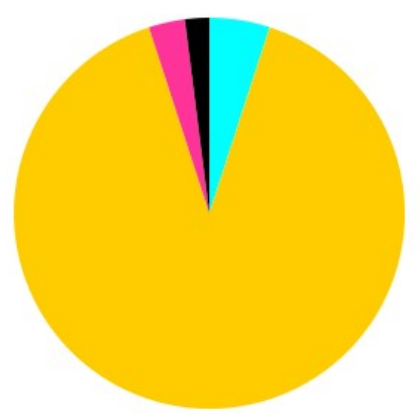

Chylomicron
$0.95-1.005$

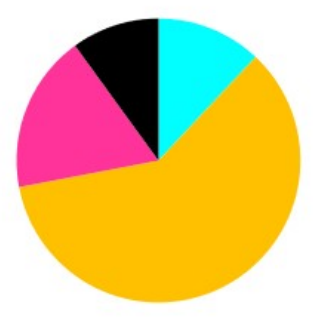

VLDL
$1.006-1.018$

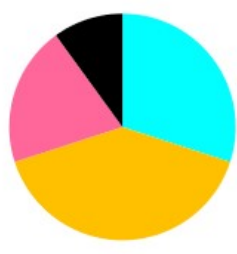

IDL
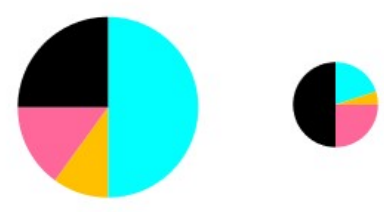

$1.019-1.0631 .063<$ density

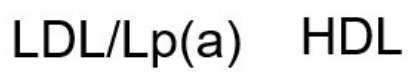

Figure 1. Lipid content of each lipoprotein. Light blue indicates cholesterol. Orange indicates triglycerides. Pink indicates phospholipid. Black indicates apolipoprotein. Chylomicron, very lowdensity lipoprotein (VLDL), and intermediate-density lipoprotein (IDL) are recognized as triglyceriderich lipoproteins, and LDL is regarded as cholesterol lipoprotein.

\section{Triglycerides and ASCVD}

Triglyceride-rich lipoproteins are larger than LDL, and their penetration into arterial walls has been presumed to be limited to biophysical considerations alone. However, both apoB100 and apoB48 can be extracted from atherosclerotic plaque [8]. Accumulating experimental evidence suggests that VLDL can penetrate into the vessel intima, contributing to the development of atherosclerosis, whereas chylomicron and chylomicron remnants are too large to penetrate into the endothelial layer. Moreover, the triglyceride-rich lipoproteins do not need to undergo oxidative modification to be incorporated into macrophages because the macrophages recognize apolipoprotein $\mathrm{E}$ on the lipoproteins' surface, triggering lipoprotein uptake $[9,10]$. It is therefore biologically plausible that triglyceride-rich lipoproteins are atherogenic. Furthermore, triglycerides are significantly associated with risk of ASCVD even in patients with familial hypercholesterolemia (FH) mainly caused by LDL receptor dysfunction, where LDL cholesterol is critically increasing their risk for ASCVD [11].

In addition to those clinical data, a useful scheme can illustrate a causal association between factors (typically a biomarker) and outcomes. In contrast to randomized controlled trials (RCTs), which need extensive time and effort, the Mendelian randomization study utilizes certain genotypes as instruments to assess a causal association between biomarkers and outcomes (Figure 2) [12]. This approach can be considered as a proxy of an RCT, wherein we can assume that the confounding variables could be randomized evenly. Therefore, this interesting approach can be considered a natural RCT. In the case of triglycerides, recent Mendelian randomization studies show causal relationships with ASCVD. Using common genetic variations, Do et al., conducted an interesting study creating different 12 logistic models to determine whether triglycerides causally influence risk for ASCVD. They adjusted 
the effects of LDL cholesterol and/or HDL cholesterol levels on ASCVD risk in the models, and found that the triglyceride level conferred by single nucleotide polymorphisms associated with triglyceride levels was significantly associated with risk for ASCVD [13]. Moreover, they also showed robust associations between rare genetic variations associated with triglycerides and ASCVD risk in targeted and exome-wide analyses [14,15]. Interestingly, the gene-based association testing indicated that rare genetic variations associated with lower triglycerides were consistently associated with reduced risk for ASCVD [16]. These facts, ranging from clinical data and genetic studies with common as well as rare variants, collectively suggest that triglycerides are causally associated with ASCVD.

Randomized controlled trial

Eligible participants

$\downarrow$

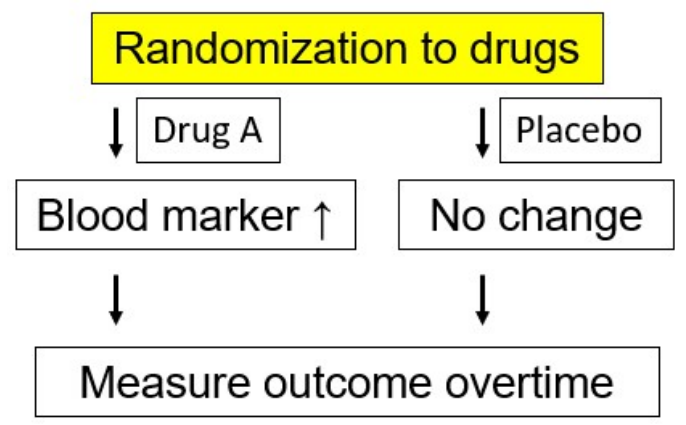

Mendelian randomization study
Eligible participants

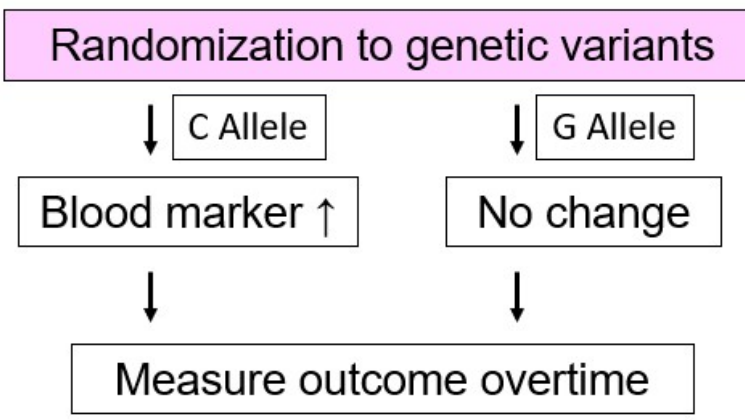

Figure 2. Scheme of randomized controlled trial and Mendelian randomization studies. The left panel indicates a randomized controlled trial. The right panel indicates a Mendelian randomized study. In a randomized controlled trial, participants are typically randomized either to placebo or actual drug, then we measure blood markers and associated outcomes. In this case, we can assume that intervention using particular drug associated with changes in blood marker lead to the changes in outcomes. On the other hand, in a Mendelian randomized study, participants are randomized to particular alleles, then we measure blood markers and associated outcomes. In this case, we can regard it as a proxy of a randomized controlled trial.

\section{Lessons from Extreme Cases (Severe Hypertriglyceridemia)}

With regard to the association between triglycerides and ASCVD, researchers, including ourselves, have reported that significantly elevated triglyceride level $(>1000 \mathrm{mg} / \mathrm{dL})$ is not always associated with ASCVD [17]. In addition, ASCVD is not frequently observed in cases with lipoprotein lipase (LPL) deficiency, with triglyceride levels typically significantly elevated [18], although heterozygous mutation carrier has been associated with ASCVD [14].

\section{Interventions for Hypertriglyceridemia}

Body weight control and dietary modification are effective treatments for hypertriglyceridemia $[19,20]$. This may include restricting intake of carbohydrate, alcohol and omega-3 fatty acid [21]. Medications could be considered for patients with elevated triglyceride levels that do not respond to lifestyle changes. Fibrates could be considered first, based on RCTs, including the Helsinki Heart Study (HHS), Bezafibrate Infarction Prevention (BIP), Veterans Affairs high-density lipoprotein intervention trial, Fenofibrate Intervention and Event Lowering in Diabetes (FIELD), the Action to Control Cardiovascular Risk in Diabetes (ACCORD), and Diabetes Atherosclerosis Intervention Study (DAIS) showing beneficial effects in patients with elevated triglycerides and decreased HDL cholesterol levels [22-27]. 
Moreover, a novel peroxisome proliferator-activated receptor $\alpha$ (PPAR $\alpha)$ modulator (SPPARM $\alpha)$ called pemafibrate showed higher potency and selectivity for activation of PPAR $\alpha$ compared with fenofibrate [28]. This new drug is associated with fewer adverse effects and further reduction of triglyceride levels [29]. On the other hand, beneficial effect of omega-3 polyunsaturated fatty acids (n-3 PUFAs) to prevent ASCVD has been controversial. Although accumulated data from RCTs have not provided definitive evidence to reduce ASCVD risk using n-3 PUFA, many studies so far had several problems, including low dosage of n-3 PUFA and no assessment of triglycerides [30]. Upcoming trials using larger dosages of n-3 PUFA, and targeting patients with higher risk could illuminate the efficacy of this type of drug in ASCVD risk management.

Another way to reduce triglyceride is through apolipoprotein-C3 (APOC3) inhibition using anti-sense techniques. APOC3 plays a pivotal role in triglyceride-rich lipoprotein metabolism. Based on the findings from a Mendelian randomization study investigating the association between loss-of-function mutation in the APOC 3 gene and ASCVD, APOC3 inhibition seems to reduce triglycerides and coronary heart disease events [31]. It has been shown that anti-sense oligonucleotides could reduce triglycerides in patients with hypertriglyceridemia by $\sim 70 \%$ [32].

\section{Fasting State or Post-prandial (Non-fasting) State?}

Usually, serum triglyceride is assessed at fasting state. However, those assessments may not reflect average serum triglyceride levels and the associated risk for ASCVD. Measuring triglycerides in the post-prandial state has several advantages over fasting measurements. People in general are in almost always in a post-prandial state, which allows blood sampling without the need for fasting. On the other hand, if the Friedewald equation is used, LDL cholesterol may be underestimated with the presence of chylomicrons [33]. In addition, many RCTs used fasting triglyceride, and they provided evidence for risk assessment to prevent ASCVD. However, other epidemiological studies and major RCTs with statins used triglyceride levels assessed at post-prandial state, leading us to change our clinical practice using non-fasting blood samples [34-37]. In addition, in most of the Mendelian randomization and association studies focusing on the association between triglycerides and ASCVD outcomes, triglyceride levels were mainly measured in a non-fasting state [13-15,31]. Therefore, the European Atherosclerosis Society and European Federation of Clinical Chemistry and Laboratory Medicine (EAS/EFLM)'s joint consensus statement recommended that non-fasting blood samples should be routinely used for plasma lipid profile assessments [38]. However, we also recommend assessments in the fasting state because subjects may have some genetic or secondary causes of hypertriglyceridemia [17,18]. Moreover, it has been shown that post-prandial increase of triglycerides or remnant lipoproteins are one of the major causes for the development of ASCVD [39]. In addition, we have shown that the difference in such changes in post-prandial increase of triglycerides or remnant lipoproteins could be a factor for the phenotypic difference in similar diseases, such as FH, sitosterolemia, and autosomal recessive hypercholesterolemia (ARH) [40,41]. Accordingly, checking the post-prandial increase of such lipoproteins could be useful when assessing their ASCVD risk in detail, including in extreme situations.

\section{Residual Risk Factor for ASCVD}

Many researchers have been investigating for "residual" risk factors since the beneficial effect of statins was established [42]. Among these, triglycerides are associated with residual ASCVD events under the situation of adequate statin therapies (Figure 3) [5,43]. Furthermore, the studies showing such associations between triglycerides and residual ASCVD were high quality RCTs with a sufficient sample size. Only a few biomarkers, including triglycerides, have a good supporting "evidence" with high quality. 

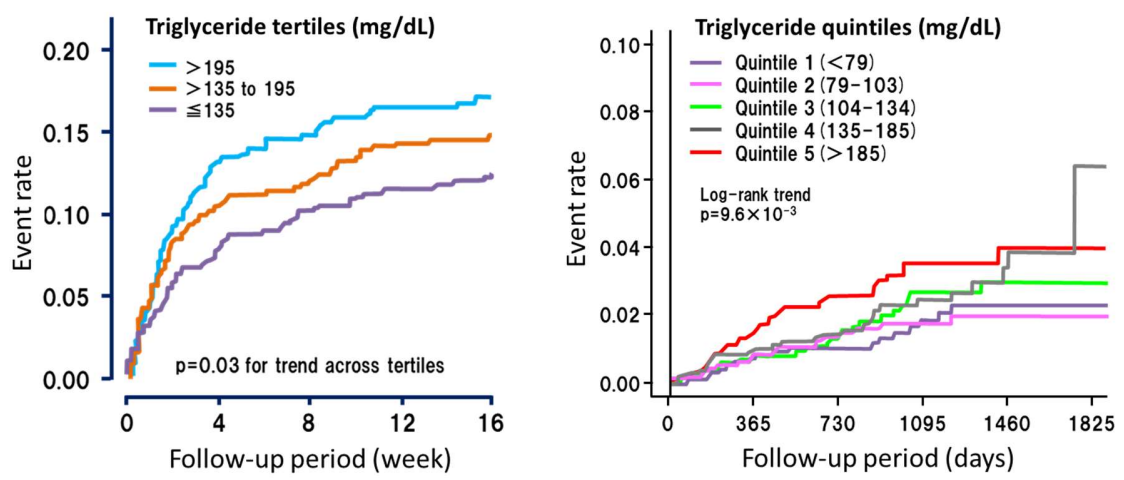

Figure 3. Cardiac events and triglycerides under statin therapies. The left panel shows short-term events after acute coronary syndrome (The Myocardial Ischemia Reduction with Aggressive Cholesterol Lowering: MIRACLE study). The subjects were divided according to tertiles of baseline triglyceride levels. The right panel shows the long-term events in the primary prevention group (standard versus intEnsive statin therapy for hypercholesteroleMic Patients with diAbetic retinopathy: EMPATHY study). The subjects were divided according to quintiles of baseline triglyceride levels. Both results strongly suggest that triglyceride is a residual risk factor under sufficient statin therapy for the development of ASCVD.

\section{LPL Pathway and ASCVD}

LPL has been shown to be one of the major drivers of catabolism of triglyceride-rich lipoproteins, including remnant lipoproteins [44]. However, determining the causal association between the LPL pathway and ASCVD development has been difficult. Recently, Kathiresan et al., investigated whether LPL pathway molecules were causally associated with ASCVD in large Mendelian randomization studies. As stated before, they showed that individuals with loss-of-function mutations in APOC3 gene exhibited lower odds for ASCVD incidents associated with lower triglycerides [31]. In addition, they found that apolipoprotein A5 missense mutations were significantly associated with early-onset of myocardial infarction [45]. Moreover, they found that rare variations in LPL gene were significantly associated with ASCVD [14]. Findings where LPL pathway molecules are consistently associated with ASCVD suggest a strong causal association between LPL pathway and ASCVD development (Figure 4).

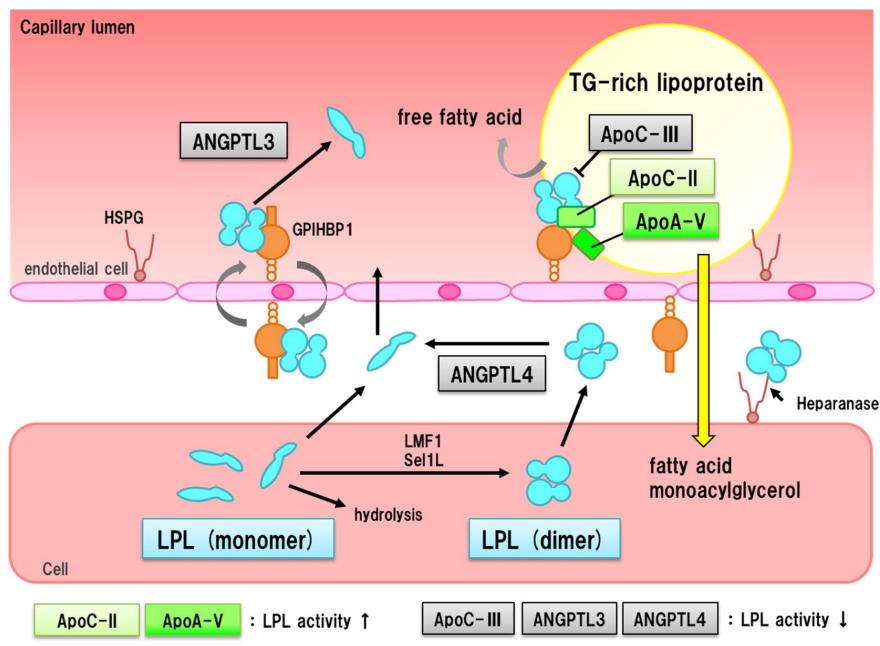

Figure 4. LPL pathway and associated proteins. Major proteins associated with LPL pathway are illustrated in this scheme. LPL is transported to endothelial cells, and binds to GPIHBP1. LPL hydrolyzes triglycerides on lipoproteins. APOC3, angiopoietin-like protein 3 (ANGPTL3), and angiopoietin-like protein 4 (ANGPTL4) play as inhibitor of LPL. On the other hand, APOC2 and APOA5 activate LPL. The fact that those proteins are significantly associated with ASCVD strongly suggests that LPL pathway is associated with the development of ASCVD. 


\section{Conclusion}

In this review, we repeatedly emphasized that triglycerides are residual, modifiable, and causal ASCVD risk factors. More attention should be paid to triglycerides, in addition to LDL cholesterol, to reduce ASCVD events further.

Author Contributions: H.T., A.N. and M.-a.K. contributed in the drafting of the manuscript.

Funding: This paper received no external funding.

Conflicts of Interest: The authors declare no conflicts of interest.

\section{References}

1. Trialists, C.T. Efficacy and safety of more intensive lowering of LDL cholesterol: A meta-analysis of data from 170,000 participants in 26 randomised trials. Lancet 2010, 376, 1670-1681.

2. Cannon, C.P.; Blazing, M.A.; Giugliano, R.P.; McCagg, A.; White, J.A.; Theroux, P.; Darius, H.; Lewis, B.S.; Ophuis, T.O.; Jukema, J.W.; et al. Ezetimibe added to statin therapy after acute coronary syndromes. N. Engl. J. Med. 2015, 372, 2387-2397. [CrossRef] [PubMed]

3. Sabatine, M.S.; Giugliano, R.P.; Keech, A.C.; Honarpour, N.; Wiviott, S.D.; Murphy, S.A.; Kuder, J.F.; Wang, H.; Liu, T.; Wasserman, S.M.; et al. Evolocumab and clinical outcomes in patients with cardiovascular disease. N. Engl. J. Med. 2017, 376, 1713-1722. [CrossRef] [PubMed]

4. Varbo, A.; Nordestgaard, B.G. Remnant cholesterol and triglyceride-rich lipoproteins in atherosclerosis progression and cardiovascular disease. Arterioscler. Thromb. Vasc. Biol. 2016, 36, 2133-2135. [CrossRef] [PubMed]

5. Tada, H.; Kawashiri, M.A.; Nomura, A.; Yoshimura, K.; Itoh, H.; Komuro, I.; Yamagishi, M. Serum triglycerides predict first cardiovascular events in diabetic patients with hypercholesterolemia and retinopathy. Eur. J. Prev. Cardiol. 2018, 25, 1852-1860. [CrossRef] [PubMed]

6. Madsen, C.M.; Varbo, A.; Nordestgaard, B.G. Unmet need for primary prevention in individuals with hypertriglyceridaemia not eligible for statin therapy according to European Society of Cardiology/European Atherosclerosis Society guidelines: A contemporary population-based study. Eur. Heart J. 2018, 39, 610-619. [CrossRef] [PubMed]

7. Lampe, M.A.; Burlingame, A.L.; Whitney, J.; Williams, M.L.; Brown, B.E.; Roitman, E.; Elias, P.M. Human stratum corneum lipids: Characterization and regional variations. J. Lipid Res. 1983, 24, 120-130. [PubMed]

8. Proctor, S.D.; Mamo, J.C. Intimal retention of cholesterol derived from apolipoprotein B100- and apolipoprotein B48-containing lipoproteins in carotid arteries of Watanabe heritable hyperlipidemic rabbits. Arterioscler. Thromb. Vasc. Biol. 2003, 23, 1595-1600. [CrossRef] [PubMed]

9. Chung, B.H.; Segrest, J.P.; Smith, K.; Griffin, F.M.; Brouillette, C.G. Lipolytic surface remnants of triglyceride-rich lipoproteins are cytotoxic to macrophages but not in the presence of high density lipoprotein. A possible mechanism of atherogenesis? J. Clin. Investig. 1989, 83, 1363-1374. [CrossRef] [PubMed]

10. Tomono, S.; Kawazu, S.; Kato, N.; Ono, T.; Ishii, C.; Ito, Y.; Shimizu, M.; Shimoyama, M.; Nakano, T.; Nakajima, K. Uptake of remnant like particles (RLP) in diabetic patients from mouse peritoneal macrophages. J. Atheroscler. Thromb. 1994, 1, 98-102. [CrossRef] [PubMed]

11. Tada, H.; Kawashiri, M.A.; Nohara, A.; Sakata, K.; Inazu, A.; Mabuchi, H.; Yamagishi, M.; Hayashi, K. Remnant-like particles and coronary artery disease in familial hypercholesterolemia. Clin. Chim. Acta 2018, 482, 120-123. [CrossRef] [PubMed]

12. Tada, H.; Kawashiri, M.A.; Yamagishi, M. Comprehensive genotyping in dyslipidemia: Mendelian dyslipidemias caused by rare variants and Mendelian randomization studies using common variants. J. Hum. Genet. 2017, 62, 453-458. [CrossRef] [PubMed]

13. Do, R.; Willer, C.J.; Schmidt, E.M.; Sengupta, S.; Gao, C.; Peloso, G.M.; Gustafsson, S.; Kanoni, S.; Ganna, A.; Chen, J.; et al. Common variants associated with plasma triglycerides and risk for coronary artery disease. Nat. Genet. 2013, 45, 1345-1352. [CrossRef] [PubMed]

14. Khera, A.V.; Won, H.H.; Peloso, G.M.; O’Dushlaine, C.; Liu, D.; Stitziel, N.O.; Natarajan, P.; Nomura, A.; Emdin, C.A.; Gupta, N.; et al. Association of Rare and Common Variation in the lipoprotein lipase gene with coronary artery disease. JAMA 2017, 317, 937-946. [CrossRef] [PubMed] 
15. Liu, D.J.; Peloso, G.M.; Yu, H.; Butterworth, A.S.; Wang, X.; Mahajan, A.; Saleheen, D.; Emdin, C.; Alam, D.; Alves, A.C.; et al. Exome-wide association study of plasma lipids in $>300,000$ individuals. Nat. Genet. 2017, 49, 1758-1766. [CrossRef] [PubMed]

16. Tada, H.; Kawashiri, M.A. Genetic variations, triglycerides, and atherosclerotic disease. J. Atheroscler. Thromb. 2018, 19, 31. [CrossRef] [PubMed]

17. Tada, H.; Kawashiri, M.A.; Nakahashi, T.; Yagi, K.; Chujo, D.; Ohbatake, A.; Mori, Y.; Mori, S.; Kometani, M.; Fujii, H.; et al. Clinical characteristics of Japanese patients with severe hypertriglyceridemia. J. Clin. Lipidol. 2015, 9, 519-524. [CrossRef] [PubMed]

18. Teramoto, R.; Tada, H.; Kawashiri, M.A.; Nohara, A.; Nakahashi, T.; Konno, T.; Inazu, A.; Mabuchi, H.; Yamagishi, M.; Hayashi, K. Molecular and functional characterization of familial chylomicronemia syndrome. Atherosclerosis 2018, 269, 272-278. [CrossRef] [PubMed]

19. Appel, L.J.; Sacks, F.M.; Carey, V.J.; Obarzanek, E.; Swain, J.F.; Miller, E.R., 3rd; Conlin, P.R.; Erlinger, T.P.; Rosner, B.A.; Laranjo, N.M.; et al. Effects of protein, monounsaturated fat, and carbohydrate intake on blood pressure and serum lipids: Results of the OmniHeart randomized trial. JAMA 2005, 294, 2455-2464. [CrossRef] [PubMed]

20. Miller, M.; Stone, N.J.; Ballantyne, C.; Bittner, V.; Criqui, M.H.; Ginsberg, H.N.; Goldberg, A.C.; Howard, W.J.; Jacobson, M.S.; Kris-Etherton, P.M.; et al. Triglycerides and cardiovascular disease: A scientific statement from the American Heart Association. Circulation 2011, 123, 2292-2333. [CrossRef] [PubMed]

21. Rimm, E.B.; Appel, L.J.; Chiuve, S.E.; Djoussé, L.; Engler, M.B.; Kris-Etherton, P.M.; Mozaffarian, D.; Siscovick, D.S.; Lichtenstein, A.H.; American Heart Association Nutrition Committee of the Council on Lifestyle and Cardiometabolic Health; et al. Seafood Long-Chain n-3 polyunsaturated fatty acids and cardiovascular Disease: A Science Advisory From the American Heart Association. Circulation 2018, 138, e35-e47. [CrossRef] [PubMed]

22. Frick, M.H.; Elo, O.; Haapa, K.; Heinonen, O.P.; Heinsalmi, P.; Helo, P.; Huttunen, J.K.; Kaitaniemi, P.; Koskinen, P.; Manninen, V.; et al. Helsinki Heart Study.Primary-prevention trial with gemfibrozil in middle-aged men with dyslipidemia. Safety of treatment, changes in risk factors, and incidence of coronary heart disease. N. Engl. J. Med. 1987, 317, 1237-1245. [CrossRef] [PubMed]

23. Bezafibrate Infarction Prevention (BIP) Study. Secondary prevention by raising HDL cholesterol and reducing triglycerides in patients with coronary artery disease. Circulation 2000, 102, 21-27. [CrossRef]

24. Rubins, H.B.; Robins, S.J.; Collins, D.; Nelson, D.B.; Elam, M.B.; Schaefer, E.J.; Faas, F.H.; Anderson, J.W. Diabetes, plasma insulin, and cardiovascular disease: Subgroup analysis from the Department of Veterans Affairs high-density lipoprotein intervention trial (VA-HIT). Arch. Intern. Med. 2002, 162, 2597-2604. [CrossRef] [PubMed]

25. Sullivan, D.; Forder, P.; Simes, J.; Whiting, M.; Kritharides, L.; Merrifield, A.; Donoghoe, M.; Colman, P.G.; Graham, N.; Haapamäki, H.; et al. Associations between the use of metformin, sulphonylureas, or diet alone and cardiovascular outcomes in 6005 people with type 2 diabetes in the FIELD study. Diabetes Res. Clin. Pract. 2011, 94, 284-290. [CrossRef] [PubMed]

26. ACCORD Study Group; Ginsberg, H.N.; Elam, M.B.; Lovato, L.C.; Crouse, J.R., 3rd; Leiter, L.A.; Linz, P.; Friedewald, W.T.; Buse, J.B.; Gerstein, H.C.; et al. Effects of combination lipid therapy in type 2 diabetes mellitus. N. Engl. J. Med. 2010, 362, 1563-1574. [PubMed]

27. Diabetes Atherosclerosis Intervention Study Investigators. Effect of fenofibrate on progression of coronary-artery disease in type 2 diabetes: The Diabetes Atherosclerosis Intervention Study, a randomised study. Lancet 2001, 357, 905-910. [CrossRef]

28. Fruchart, J.C. Pemafibrate (K-877), a novel selective peroxisome proliferator-activated receptor $\alpha$ modulator for management of atherogenic dyslipidaemia. Cardiovasc. Diabetol. 2017, 16, 124. [CrossRef] [PubMed]

29. Arai, H.; Yamashita, S.; Yokote, K.; Araki, E.; Suganami, H.; Ishibashi, S.; K-877 Study Group. Efficacy and safety of Pemafibrate Versus fenofibrate in patients with high triglyceride and low HDL cholesterol levels: A multicenter, placebo-controlled, double-blind, randomized trial. J. Atheroscler. Thromb. 2018, 25, 521-538. [CrossRef] [PubMed]

30. Abdelhamid, A.S.; Martin, N.; Bridges, C.; Brainard, J.S.; Wang, X.; Brown, T.J.; Hanson, S.; Jimoh, O.F.; Ajabnoor, S.M.; Deane, K.H.; et al. Polyunsaturated fatty acids for the primary and secondary prevention of cardiovascular disease. Cochrane Database Syst. Rev. 2018, 7, CD012345. [CrossRef] [PubMed] 
31. TG and HDL Working Group of the Exome Sequencing Project, National Heart, Lung, and Blood Institute; Crosby, J.; Peloso, G.M.; Auer, P.L.; Crosslin, D.R.; Stitziel, N.O.; Lange, L.A.; Lu, Y.; Tang, Z.Z.; Zhang, H.; et al. Loss-of-function mutations in APOC3, triglycerides, and coronary disease. N. Engl. J. Med. 2014, $371,22-31$.

32. Gaudet, D.; Alexander, V.J.; Baker, B.F.; Brisson, D.; Tremblay, K.; Singleton, W.; Geary, R.S.; Hughes, S.G.; Viney, N.J.; Graham, M.J.; et al. Antisense inhibition of apolipoprotein C-III in patients with hypertriglyceridemia. N. Engl. J. Med. 2015, 373, 438-447. [CrossRef] [PubMed]

33. Martin, S.S.; Blaha, M.J.; Elshazly, M.B.; Toth, P.P.; Kwiterovich, P.O.; Blumenthal, R.S.; Jones, S.R. Comparison of a novel method vs the Friedewald equation for estimating low-density lipoprotein cholesterol levels from the standard lipid profile. JAMA 2013, 310, 2061-2068. [CrossRef] [PubMed]

34. Freiberg, J.J.; Tybjaerg-Hansen, A.; Jensen, J.S.; Nordestgaard, B.G. Nonfasting triglycerides and risk of ischemic stroke in the general population. JAMA 2008, 300, 2142-2152. [CrossRef] [PubMed]

35. Bansal, S.; Buring, J.E.; Rifai, N.; Mora, S.; Sacks, F.M.; Ridker, P.M. Fasting compared with nonfasting triglycerides and risk of cardiovascular events in women. JAMA 2007, 298, 309-316. [CrossRef] [PubMed]

36. Sever, P.S.; Dahlöf, B.; Poulter, N.R.; Wedel, H.; Beevers, G.; Caulfield, M.; Collins, R.; Kjeldsen, S.E.; Kristinsson, A.; McInnes, G.T.; et al. Prevention of coronary and stroke events with atorvastatin in hypertensive patients who have average or lower-than-average cholesterol concentrations, in the Anglo-Scandinavian Cardiac Outcomes Trial-Lipid Lowering Arm (Ascot-LLA): A multicentre randomised controlled trial. Lancet 2003, 361, 1149-1158. [PubMed]

37. SEARCH Study Collaborative Group; Bowman, L.; Armitage, J.; Bulbulia, R.; Parish, S.; Collins, R. Study of the effectiveness of additional reductions in cholesterol and homocysteine (SEARCH): Characteristics of a randomized trial among 12064 myocardial infarction survivors. Am. Heart J. 2007, 154, 815-823. [PubMed]

38. Stone, N.J.; Robinson, J.G.; Lichtenstein, A.H.; Bairey Merz, C.N.; Blum, C.B.; Eckel, R.H.; Goldberg, A.C.; Gordonz, D.; Levy, D.; Lloyd-Jones, D.M.; et al. 2013 ACC/AHA guideline on the treatment of blood cholesterol to reduce atherosclerotic cardiovascular risk in adults: A report of the American College of Cardiology/American Heart Association Task Force on Practice Guidelines. J. Am. Coll. Cardiol. 2014, 63, 2889-2934. [CrossRef] [PubMed]

39. Borén, J.; Matikainen, N.; Adiels, M.; Taskinen, M.R. Postprandial hypertriglyceridemia as a coronary risk factor. Clin. Chim. Acta 2014, 431, 131-142. [CrossRef] [PubMed]

40. Tada, H.; Kawashiri, MA.; Tanaka, A.; Nakano, T.; Nakajima, K.; Inoue, T.; Noguchi, T.; Nakanishi, C.; Konno, T.; Hayashi, K.; et al. Post-prandial remnant lipoprotein metabolism in autosomal recessive hypercholesterolaemia. Eur. J. Clin. Investig. 2012, 42, 1094-1099. [CrossRef] [PubMed]

41. Tada, H.; Nomura, A.; Nohara, A.; Inazu, A.; Mabuchi, H.; Yamagishi, M.; Kawashiri, M.A. Post-prandial Remnant Lipoprotein Metabolism in Sitosterolemia. J. Atheroscler. Thromb. 2018. [CrossRef] [PubMed]

42. Reith, C.; Armitage, J. Management of residual risk after statin therapy. Atherosclerosis 2016, 245, 161-170. [CrossRef] [PubMed]

43. Schwartz, G.G.; Abt, M.; Bao, W.; DeMicco, D.; Kallend, D.; Miller, M.; Mundl, H.; Olsson, A.G. Fasting triglycerides predict recurrent ischemic events in patients with acute coronary syndrome treated with statins. J. Am. Coll. Cardiol. 2015, 65, 2267-2275. [CrossRef] [PubMed]

44. Sato, K.; Okajima, F.; Miyashita, K.; Imamura, S.; Kobayashi, J.; Stanhope, K.L.; Havel, P.J.; Machida, T.; Sumino, H.; Murakami, M.; et al. The majority of lipoprotein lipase in plasma is bound to remnant lipoproteins: A new definition of remnant lipoproteins. Clin. Chim. Acta 2016, 461, 114-125. [CrossRef] [PubMed]

45. Do, R.; Stitziel, N.O.; Won, H.H.; Jørgensen, A.B.; Duga, S.; Angelica Merlini, P.; Kiezun, A.; Farrall, M.; Goel, A.; Zuk, O.; et al. Exome sequencing identifies rare LDLR and APOA5 alleles conferring risk for myocardial infarction. Nature 2015, 518, 102-106. [CrossRef] [PubMed]

(C) 2018 by the authors. Licensee MDPI, Basel, Switzerland. This article is an open access article distributed under the terms and conditions of the Creative Commons Attribution (CC BY) license (http:/ / creativecommons.org/licenses/by/4.0/). 